Journal of Innovative Image Processing (JIIP) (2019)

Vol.01/ No. 02

Pages: $81-90$

https://www.irojournals.com/iroiip/

DOI: https://doi.org/10.36548/jiip.2019.2.003

\title{
TECHNIQUES FOR ENHANCEMENT AND DENOISING OF UNDERWATER IMAGES: A REVIEW
}

\author{
Dr. P. Karuppusamy, \\ Department of EEE, \\ Shree Venkateshwara Hi-Tech Engineering College, \\ Erode, India. \\ Email id: pkarrupusamyphd@gmail.com
}

\begin{abstract}
The images observed from the underwater are usually of low quality because of the scattering of lights, ripples in water and the organic matters resolved in the water. So the preprocessing becomes an important necessity for the images obtained from under water before subjected to the future operations. The various degree of distortions suffered from by the underwater images could be preprocessed by applying the denoising and the image enhancement techniques. The Review addressing the techniques available in enhancing and denoising the underwater images is presented in the paper.
\end{abstract}

Keywords: Preprocessing, Image Denoising, Image Enhancement, Filtering, Contrast Stretching, Under Water Images

\section{INTRODUCTION}

The preprocessing techniques such as the image enhancement and the denoising applied to the images are the methods that take in the low quality images as the input to make it clearer and perceptible and improving the information content of the image as well as modifying its visual impact. The features of the images are intensified applying the image enhancement methods [1-2].

The image enhancement techniques subdues the noise, protects the edges of the images followed by enhancing and smoothing of the image to make them more useful for the further analysis or the study [3-4].

The review in the paper concentrates techniques to improve the poor quality images obtained from the river beds and the oceans. The images form the under waters are usually collected by the people interested in oceanography while floating on water, scuba diving, by diving from a submarine or a boat, and programmed cameras that travel deep inside the water to observe the creatures living inside the deep water beds or the trench's [5-8]

ISSN: 2582- 4252

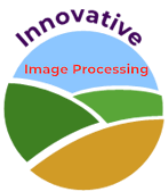


Journal of Innovative Image Processing (JIIP) (2019)

Vol.01/ No. 02

Pages: $81-90$

https://www.irojournals.com/iroiip/

DOI: https://doi.org/10.36548/jiip.2019.2.003

In the water surface the light spreads and gets observed un-uniformly, deep inside the water only the low wavelength of the natural light will be observed by the water with only blue only blue and green light being visible. The light propagates in the water using the absorption and the scattering, influencing the complete performance of the imaging system that is in the underwater. The images taken gets blurred due to the forward scattering and the backward scattering causes the contrast problem in the images resulting in uneven illumination, with the low contrast and the poor quality of images [9-12]

So the images acquired form the underwater are projected through certain image processing steps before subjected to the further computation or the research work. The Figure.1 below provides the stages of the image processing to regain the quality of the underwater images.

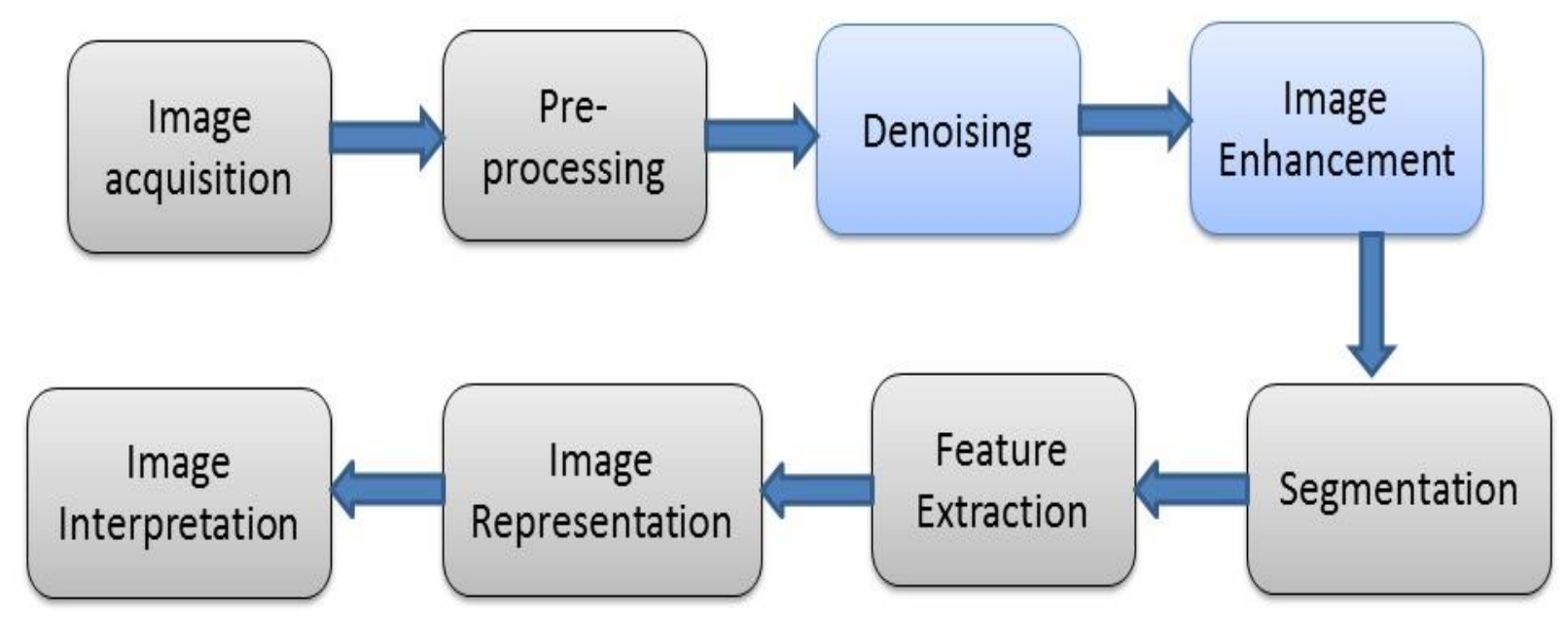

Figure.1 Stages of the Image Processing

The image processing involves many stages such as the, image acquisition is done using either the underwater cameras or the underwater imaging system, the images acquired are preprocessed initially to balance the contrast and the illumination in the images followed by the next two stages to improve the quality of the images, further the segmentation simplifies the representation of the images to make it easier to analyze, the feature extraction isolates

ISSN: 2582- 4252 
Journal of Innovative Image Processing (JIIP) (2019)

Vol.01/ No. 02

Pages: $81-90$

https://www.irojournals.com/iroiip/

DOI: https://doi.org/10.36548/jiip.2019.2.003

the desired portions of the images, The representing and the interpreting of the images would be done gathering the location, size, shape, color, texture pattern, height and the association of the image[13-17].

The review in the paper mainly concentrate only on the denoising and the image enhancement methods utilized in the improving the quality of the underwater images. The paper proceeds with the obstacle found under water reducing the quality of the images, in section 2 followed by the over view of the image enhancement techniques utilized in improving the quality of the images acquired from the underwater in the section 3 , and the conclusion in the section 4 .

\section{THE REASON DEGRADING THE UNDERWATER IMAGES QUALITY}

The quality of the images in the underwater are affected due to many reasons some of them are the absorption and scattering of light, mist caused by the light reflected from the surface, varying degrees of the attenuation caused by the different wavelength of light, dominance of the bluish tone, the organic matters that are dissolved in the water etc. These reasons result with the contrast loss and the color deviation in the images acquired underwater. The table. 1 below provides the reasons and the causes that degrade the low of the images gathered from under water. 
Vol.01/ No. 02

Pages: $81-90$

https://www.irojournals.com/iroiip/

DOI: https://doi.org/10.36548/jiip.2019.2.003

\begin{tabular}{|l|l|}
\hline \multicolumn{1}{|c|}{ Reasons } & \multicolumn{1}{c|}{ Causes } \\
\hline Lightening & $\begin{array}{l}\text { The primary obstacle faced by underwater } \\
\text { photographers is the loss of color and contrast when } \\
\text { submerged to any significant depth. The loss of color } \\
\text { increases not only vertically through the water column, } \\
\text { but also horizontally, so subjects farther away from the } \\
\text { camera also appear colorless and indistinct }\end{array}$ \\
\hline The imaging Aids used & $\begin{array}{l}\text { In many cases waterproof digital cameras doesn't } \\
\text { capture underwater images. The enlargement of lens } \\
\text { rises by the refraction, this features serves as an } \\
\text { advantage to photographers to obtaining very small } \\
\text { cases }\end{array}$ \\
\hline $\begin{array}{l}\text { Flashes and the ripples in } \\
\text { the water }\end{array}$ & $\begin{array}{l}\text { The use of a reflection is often regarded as the most } \\
\text { difficult aspect of underwater photography }\end{array}$ \\
\hline Image Splitting & $\begin{array}{l}\text { Split images are popular in recreational scuba } \\
\text { magazines, often showing divers swimming beneath a } \\
\text { boat, or shallow coral reefs with the shoreline seen in } \\
\text { the background }\end{array}$ \\
\hline $\begin{array}{l}\text { Lack of skilled } \\
\text { personalities }\end{array}$ & $\begin{array}{l}\text { There is the possibility of encountered poor } \\
\text { conditions, such as heavy currents, tidal pool or low } \\
\text { visibility. Underwater ducking training providers } \\
\text { provides programs to help improve divers' diving } \\
\text { technique and arts. }\end{array}$ \\
\hline
\end{tabular}

Table.1 Reasons Degrading the Underwater Image Quality

ISSN: 2582- 4252 
Journal of Innovative Image Processing (JIIP) (2019)

Vol.01/ No. 02

Pages: $81-90$

https://www.irojournals.com/iroiip/

DOI: https://doi.org/10.36548/jiip.2019.2.003

\section{IMAGE ENHANCEMENT AND DENOISING TECHNIQUES}

The enhancement of the images basically includes multitudes of processes such as contrast stretching, pseudo coloring, noise clipping and filtering. The techniques obtained for improving the quality just intensifies the selected range of the features to provide a clear visibility. The section provides few common denoising and the image enhancement techniques utilized in improving the quality of the images that were acquired from the underwater, they section elaborates few filtering techniques applied in enhancing the images followed by few common denoising algorithms that reduces the distortions found in the content of the images. The table. 2 below provides few common methodologies used in the improving the quality of the images obtained under water.

\begin{tabular}{|l|l|l|}
\hline $\begin{array}{c}\text { Image Enhancing } \\
\text { Techniques }\end{array}$ & \multicolumn{1}{|c|}{ Procedure } & \multicolumn{1}{c|}{ Attributes } \\
\hline Contrast stretching & $\begin{array}{l}\text { It is also called as normalization } \\
\text { Improves the contrast in an image by 'stretching' the range of } \\
\text { intensity values it contains to span a desired range of values. }\end{array}$ & $\begin{array}{l}\text { It can only apply a linear scaling function to the } \\
\text { image pixel values } \\
\text { The enhancement is less harsh }\end{array}$ \\
\hline $\begin{array}{l}\text { Empirical Mode } \\
\text { Decomposition }\end{array}$ & $\begin{array}{l}\text { It is exceptionally direct } \\
\text { It carries out the sitter operations over the arrangements of the data } \\
\text { until finally a stable portion is reached. } \\
\text { Disintegrates whole signal into intrinsic mode functions and } \\
\text { residues }\end{array}$ & $\begin{array}{l}\text { Versatile } \\
\text { Based on the local movement of the objects } \\
\text { The original images is broken into multitudes of } \\
\text { intrinsic mode functions and residules }\end{array}$ \\
\hline $\begin{array}{l}\text { Homomorphic } \\
\text { filtering }\end{array}$ & $\begin{array}{l}\text { This is a frequency filtering technique } \\
\text { It is utilized to fix non-uniform lighting to reinforce contrast from } \\
\text { the impression. } \\
\text { It is the most tutilized system on the grounds that it redresses non- } \\
\text { uniform lighting and sharpens the picture }\end{array}$ & $\begin{array}{l}\text { The filter can reduce the non uniform } \\
\text { illumination present in the image. }\end{array}$ \\
\hline $\begin{array}{l}\text { Anisotropic } \\
\text { Filtering }\end{array}$ & $\begin{array}{l}\text { It smoothens the pictures in the homogeneous range, conserving } \\
\text { the edges and later upgrading them } \\
\text { Diminishes relics by erasing little edges enhanced by homomorphic } \\
\text { filtering }\end{array}$ & $\begin{array}{l}\text { Disentangles picture componentsto enhance } \\
\text { picture division }\end{array}$ \\
\hline
\end{tabular}


Journal of Innovative Image Processing (JIIP) (2019)

Vol.01/ No. 02

Pages: $81-90$

https://www.irojournals.com/iroiip/

DOI: https://doi.org/10.36548/jiip.2019.2.003

\begin{tabular}{|l|l|l|}
\hline $\begin{array}{l}\text { Wavelet Denoising } \\
\text { By Average Filter }\end{array}$ & Wavelet denoising is used to stitle the noise & $\begin{array}{l}\text { This wavelet denoising gives great results } \\
\text { contrasted with other denoising routines because, } \\
\text { unlike other methods, it does not assume that the } \\
\text { coefficients are independent. Undoubtedly } \\
\text { wavelet coefficients in normal pictures have } \\
\text { enormous conditions. Besides the reckoning time } \\
\text { is short }\end{array}$ \\
\hline $\begin{array}{l}\text { Red channel } \\
\text { method }\end{array}$ & $\begin{array}{l}\text { In this method, colors associated to short wavelengths are } \\
\text { recovered, as expected for underwater images, leading to a } \\
\text { recovery of the lost contrast }\end{array}$ & $\begin{array}{l}\text { Estimates the color picks the pixels at the } \\
\text { maximum depth, estimates water light } \\
\text { transmission, does color correction }\end{array}$ \\
\hline $\begin{array}{l}\text { Histogram } \\
\text { equalization }\end{array}$ & $\begin{array}{l}\text { This is a simple and straightforward technique. } \\
\text { For modifying image intensities and contrast of image in image } \\
\text { processing using the image's histogram }\end{array}$ & $\begin{array}{l}\text { Histogram equalization is helpful in pictures } \\
\text { with backgrounds and frontal areas that are both } \\
\text { bright or both dim. } \\
\text { Produces unrealistic effects in the output images. }\end{array}$ \\
\hline $\begin{array}{l}\text { Contrast Limited } \\
\text { Adaptive } \\
\text { Histogram } \\
\text { Equalization }\end{array}$ & $\begin{array}{l}\text { It is generalization of adaptive histogram equalization. With this } \\
\text { technique the image is broken up into tiles. The gray scale is } \\
\text { calculated for each of these tiles, based upon its histogram and } \\
\text { transform function, which is derived from the interpolation between } \\
\text { the manipulated histograms of the neighboring sub-regions. }\end{array}$ & $\begin{array}{l}\text { Limits noise enhancement unlike the Adaptive } \\
\text { Histogram Equalization. }\end{array}$ \\
\hline $\begin{array}{l}\text { Integrated color } \\
\text { model }\end{array}$ & $\begin{array}{l}\text { Does color harmonizing, improving the contrast of the RGB colors } \\
\text { space and adjustment in the HIS model }\end{array}$ & $\begin{array}{l}\text { Enhances the True color diminishing the un even } \\
\text { illumination }\end{array}$ \\
\hline
\end{tabular}

Table. 2 Image Enhancement Techniques

ISSN: 2582- 4252 
Journal of Innovative Image Processing (JIIP) (2019)

Vol.01/ No. 02

Pages: $81-90$

https://www.irojournals.com/iroiip/

DOI: https://doi.org/10.36548/jiip.2019.2.003

The images acquired from under waters hold very poor picture quality because of the nature of the light, as the light entering into the water gets scattered in various directions. The various color wavelengths of the light reaches the various depths of the water only the wavelength with the blue reaches the deep inside the water and this is the reason why the underwater images remain blue and green when captured. This also results with certain noise level affecting the image quality. The figure. 2 below provides the various noise levels affecting the pictures gathered from under water.



Figure.2 Classification of Image noise

The Gaussian noise is common noise found with the factors that are unstable in the imaging system, the salt and the pepper noise indicates the small and a large scale values on selected pixels or region, fixed mode noise occurs due to the presence of the imperfections in the devices found in the systems. So in order to tackle them the review present few denoising techniques available to reduce the noise levels in the pictures in the table. 3 below 
Journal of Innovative Image Processing (JIIP) (2019)

Vol.01/ No. 02

Pages: $81-90$

https://www.irojournals.com/iroiip/

DOI: https://doi.org/10.36548/jiip.2019.2.003

\begin{tabular}{|l|l|}
\hline Denoising Algorithms & \multicolumn{1}{|c|}{ Descriptions } \\
\hline The Median Filter & $\begin{array}{l}\text { The Median Filtering is a nonlinear signal processing method } \\
\text { which can } \\
\text { overcome the image detail blur caused by linear filtering under } \\
\text { certain conditions and effective for } \\
\text { filtering pulse noise and image scanning noise. The median filter } \\
\text { not only removes noise but also } \\
\text { protects the edges of the image which can obtain a more } \\
\text { satisfactory recovery effect. It's convenient } \\
\text { that the Statistical Properties of Images is not necessary. } \\
\text { However, the Median Filtering is not suitable } \\
\text { for processing the image with a lot of points, lines, spire details }\end{array}$ \\
\hline Average filter & $\begin{array}{l}\text { It is categorized into three types as Average filter and the } \\
\text { geometric average filter, harmonic averaging filter. }\end{array}$ \\
\hline $\begin{array}{l}\text { The Adaptive Wiener } \\
\text { Filter }\end{array}$ & $\begin{array}{l}\text { The Adaptive Filter can adjust the current filter parameters by the } \\
\text { filter parameters that can be obtained empirically which make it } \\
\text { adapt to the statistical properties of unknown or time-varying of } \\
\text { signals and noise. The smoothing effect of the filter is small when } \\
\text { the local variance is large and stronger when the local variance is } \\
\text { small. The ultimate goal of the Adaptive Wiener Filter is to } \\
\text { minimize Mean Square Error of the restoring as well as the } \\
\text { original image. }\end{array}$ \\
\hline Wavelet denoising & $\begin{array}{l}\text { The basic methods of wavelet denoising are: The wavelet } \\
\text { transform modulus maxima denoising; The wavelet transform } \\
\text { inter-scale correlation denoising; The nonlinear wavelet threshold } \\
\text { denoising. }\end{array}$ \\
\hline
\end{tabular}

Table.3 Denoising Algorithms

The image enhancement and the denoising techniques elaborated in the paper aid in the image based applications, to restore the originality of the images acquired from the underwater.

ISSN: 2582- 4252

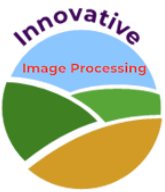


Journal of Innovative Image Processing (JIIP) (2019)

Vol.01/ No. 02

Pages: $81-90$

https://www.irojournals.com/iroiip/

DOI: https://doi.org/10.36548/jiip.2019.2.003

\section{CONCLUSION}

The paper presents the review of the underwater image enhancement and the denoising techniques presenting the reasons behind the quality degradation of the underwater images followed by the techniques to enhance and denoising the pictures observed. In future the paper is to subject the techniques reviewed in analyzing image enhancement achieved in restoring the damaged archeological artifacts.

\section{References}

[1] Shirkande, Shrinivas T., and M. J. Lengare. "Optimization of Underwater Image Enhancement Technique by Combining WCID and Wavelet Transformation Technique." In 2017 International Conference on Computing, Communication, Control and Automation (ICCUBEA), pp. 1-6. IEEE, 2017.

[2] Iqbal, Kashif, Rosalina Abdul Salam, Azam Osman, and Abdullah Zawawi Talib. "Underwater Image Enhancement Using an Integrated Colour Model." IAENG International Journal of Computer Science 34, no. 2 (2007).

[3] Arnold-Bos, Andreas, Jean-Philippe Malkasse, and Gilles Kervern. "A preprocessing framework for automatic underwater images denoising." 2005.

[4] Bazeille, Stephane, Isabelle Quidu, Luc Jaulin, and Jean-Philippe Malkasse. "Automatic underwater image pre-processing." 2006.

[5] Mangla, Gaurav, and Sukhjinder Singh. "A Review of Enhancement Techniques of Underwater Images." International Journal of Engineering and Management Research (IJEMR) 5, no. 3 (2015): 911.

[6] Kaur, Ramdeep, and Inderpreet Kaur. "Underwater Image Enhancement-An Overview." (2018).

[7] Ingole, Miss Rutika S., and C. J. Shelke. "A Review on Various Underwater Image Denoising and Enhancement Techniques."

[8] Nunes, Jean Claude, Yasmina Bouaoune, Eric Delechelle, Oumar Niang, and Ph Bunel. "Image analysis by bidimensional empirical mode decomposition." Image and vision computing 21, no. 12 (2003): 1019-1026.

[9] Reza, Ali M. "Realization of the contrast limited adaptive histogram equalization (CLAHE) for realtime image enhancement." Journal of VLSI signal processing systems for signal, image and video technology 38, no. 1 (2004): 35-44. 
Journal of Innovative Image Processing (JIIP) (2019)

Vol.01/ No. 02

Pages: $81-90$

https://www.irojournals.com/iroiip/

DOI: https://doi.org/10.36548/jiip.2019.2.003

[10] Reza, Ali M. "Realization of the contrast limited adaptive histogram equalization (CLAHE) for realtime image enhancement." Journal of VLSI signal processing systems for signal, image and video technology 38, no. 1 (2004): 35-44.

[11] Singh, Ravindra Pal, and Manish Dixit. "Histogram equalization: a strong technique for image enhancement." International Journal of Signal Processing, Image Processing and Pattern Recognition 8, no. 8 (2015): 345-352.

[12] Kurt, Burçin, Vasif V. Nabiyev, and Kemal Turhan. "Medical images enhancement by using anisotropic filter and clahe." In 2012 International Symposium on Innovations in Intelligent Systems and Applications, pp. 1-4. IEEE, 2012.

[13] Sundaram, M., K. Ramar, N. Arumugam, and G. Prabin. "Histogram modified local contrast enhancement for mammogram images." Applied soft computing 11, no. 8 (2011): 5809-5816.

[14] Raj, Jennifer S. "A COMPREHENSIVE SURVEY ON THE COMPUTATIONAL INTELLIGENCE TECHNIQUES AND ITS APPLICATIONS." Journal of ISMAC 1, no. 03 (2019): 147-159.

[15] Koresh, Mr H. James Deva. "COMPUTER VISION BASED TRAFFIC SIGN SENSING FOR SMART TRANSPORT." Journal of Innovative Image Processing (JIIP) 1, no. 01 (2019): 11-19.

[16] Chandy, Abraham. "A REVIEW ON IOT BASED MEDICAL IMAGING TECHNOLOGY FOR HEALTHCARE APPLICATIONS." Journal of Innovative Image Processing (JIIP) 1, no. 01 (2019): 51-60.

[17] Smys, S., Robert Bestak, and Joy Iong-Zong Chen. "Special issue on evolutionary computing and intelligent sustainable systems." (2019): 1-1. 